\title{
Study Cultural, Morphological and Pathogenic Variation among Different Isolates of Fusarium oxysporum f. sp. lentis
}

\author{
Khushboo Dubey* and Sushil Kumar Singh \\ Department of Plant Pathology, N. D. University of Agriculture and Technology, Kumarganj, \\ Faizabad-224229, U.P., India \\ *Corresponding author
}

\section{A B S T R A C T}

Lentil (Lens culinaris Medik.), one of the major pulses cultivated and consumed in India, is also known as Masur. It has a high nutritive value and major source of dietary proteins

Keywords

Cultural, Morphological,

Pathogenic variability,

Fusarium, Lentil

\section{Article Info}

Accepted:

04 August 2018

Available Online:

10 September 2018
(25\%) after soybeans in human and animal diet. Fusarium wilt of lentil caused by Fusarium oxysporum f.sp. lentis is the most serious disease of lentil. Ten isolates of $F$. oxysporum f.sp. lentis were studied for its cultural, morphological and pathogenic variability. Pigmentation is varied among the isolates. Out of 10 isolates, 4 isolates FOLR3, FOL-V8, FOL-M6 and FOL-R9 were Purple, were dull yellowish, isolates FOL- B7, and FOL-S10, four isolates like FOL-A2, FOL-L4, FOL-S5 and FOL-S10 were white FOL-F1was light puff in colour. The size of microconidia varied between7.30 $\times 3.43$ (FOLL4) to $13.25 \times 2.68 \mu \mathrm{m}$ (FOL-S10) and macroconidia varied from $24.11 \times 4.67$ (FOL-A2) to $40.05 \times 4.71 \mu \mathrm{m}$ (FOL-V8). The number of septa in macro-conidia was mostly 3-6 and micro-conidia are mostly no septum and some are $0-1$. Chlamydospores are terminal and intercalary. Pathogenic variability revealed that most of the isolates were highly pathogenic.

\section{Introduction}

Lentil (Lens culinaris Medik.), is a member of Leguminaceae family and it is commonly known as masoor or poor man's meat. It has a high nutritive value and major source of dietary proteins $(25 \%)$ after soybeans in human and animal diet (Rahman et al., 2010). It is cultivated as a rain fed crop in all India about 1.34 million ha area with $1.02 \mathrm{mt}$ production and $759 \mathrm{~kg} / \mathrm{ha}$ productivity (Abraham, 2015). In India lentil is predominantly grown in the North, particularly in Uttar Pradesh, Madhya
Pradesh, Bihar and West Bengal. In Uttar Pradesh, it is grown in $620.000 \mathrm{lakh} / \mathrm{ha}$ area with 452.000 lakh tones production and 732.0 $\mathrm{kg} / \mathrm{ha}$ productivity (Ahmad, 2017). It suffers from a number of diseases. Wilt of lentil caused by Fusarium oxysporum $f$. sp. lentis is one of the most wide spread and destructive disease where ever crop is grown. The yield losses due to this disease as much as 50 percent have been reported in India (Anonymous, 1999). The disease manifests as mortality of young seedlings (within 25 to30 days after sowing) to wilting or death of adult plants. Early wilting causes more loss than late 
wilting, but seeds from late-wilted plants are lighter, rough and dull than those from healthy plants (Haware, 1980) The roots of the wilting plants don't show any external rotting but when split open vertically, dark brown discoloration of internal xylem is seen (Nene, 1991).

The pathogen is facultative saprophytic and it can survive as mycelium and chlamydospores in seed, soil and also on infected crops residues, buried in the soil for up to five to six years (Haware, 1986). The fungus produced macro-conidia and micro-conidia and also chlamydospores. Fungal chlamydospores can survive in soil up to six years in the absence of the host plants (Haware, 1996) In view of the above facts, the present research work was aimed to carryout comprehensive investigation on the cultural, morphological, physiological and pathogenic variation of Fusarium oxysporum f. sp. lentil.

\section{Materials and Methods}

\section{Isolation of Fusarium oxysporum f.sp. lentis isolates}

Small pieces of infected root 1-2 $\mathrm{mm}$ dimension from the advancing margin of the spot, adjacent to healthy portions were cut with blade, washed well in distilled water to remove dust adhered to the infected pieces. Pieces were dipped in 0.1 per cent mercuric chloride solution for 30 seconds and finally washed well in three changes of sterilized distilled water. The bits were then transferred to PDA medium in Petri plates with the help of inoculating needle under aseptic condition and incubated at $28 \pm 1{ }^{\circ} \mathrm{C}$. Pure culture was done by transfer of a pinch of mycelium on sterilized Potato Dextrose Agar medium in Petriplates and incubated in BOD. The fungus was identified by colony growth, pigmentation and microscopic charactertics of Fusarium oxysporum.
Cultural, morphological and pathogenic variation

The cultural characters of isolates of $F$. oxysporum f. sp. lentis were recorded from culture grown on PDA. Twenty ml of PDA was poured in each of previously sterilized petri plates. Five $\mathrm{mm}$ discs were cut through sterilized cork borer from the margin of seven days old colony of the fungal culture grown in petri plates. One disc was placed in the centre of each plate and incubated at $28 \pm 1^{0} \mathrm{C}$ for seven days. Three replications were maintained for each isolate. The differences between observations regarding colony color, Growth rate, colony pattern and type of mycelial growth of each isolate were taken. The slides of 10 isolates were prepared in lactophenol and cotton blue from 10 days old culture. For morphological studies, 25 observations for size of macro and micro conidia and number of conidia per microscopic field belonging to each isolates were taken under high power (100x) microscopic field. These isolates were categorized in various groups according to shape and size of macro and micro conidia, length and width of conidia, no. of septa and chalamydospore.

\section{Pathogenicity test of the pathogen}

The pathogenic test conducted in the glass house condition in pots. It is Sterilized sick soil. The inoculum was prepared by growing pure culture of Fusariurn oxysporum $f$. $s p$. lentil on PDA for 10 days and inoculation of the soil was done 2 days before sowing of seed by mixing of the soil with fungus culture in pots. Control pots were filled with soil without adding inoculum. Healthy and surface sterilized seed of lentil variety L-9-12 were first disinfected with $2.5 \%$ sodium hypochloride solution for 3 minutes and then rinsed with sterilized water, dried and sown with 20 seeds/pot. The seeds were sown in 30 
$\mathrm{cm}$ diameter earthen pots. The pots were then transferred in glass house and irrigated regularly to maintain sufficient moisture.

The pots kept in glass house were observed critically for seedlings emergence and appearance of symptoms on seedlings and adult plant up to 60 days of sowing. The emergence of the seedling was recorded on $15^{\text {th }}$ day after sowing. The pathogen was reisolated from the internal tissue of infected plant in PDA medium for confirmation of (Koch's postulates, 1883).

\section{Results and Discussion}

Symptomatic (wilted) plants were collected from ten districts of Uttar Pradesh Viz., Kumarganj, Faizabad (FOL-F1); Nihalgarah, Amethi (FOL-A2); Amernager, Raibreilly (FOL-R3); Bakshi kitalab, Lucknow (FOLL4); Sonbhadra, Sonbhadra (FOL-S 5); Mujehra, Mirzapur (FOL-M6); Tilathi, Bhadohi (FOL-B7); Mirzamurad, Varanasi (FOL-V8); Rath, Hamirpur (FOL-R9) and Pakhrauli, Sultanpur (FOL-S10) for cultural, morphological and pathogenic variability studies of Fusarium oxysporum f. sp. lentis

The cultures were of $F$. oxysporum f. sp. lentis grown on PDA in Petri dishes at $25 \pm 1^{\circ} \mathrm{C}$ for 7 days and were used to record observations with regard to cultural characters viz., mycelium colour, substrate colour, growth pattern, and growth rates (Table 1).

\section{Mycelium colour}

Colonies of ten isolates differed considerably with regard to their mycelium colour and exhibited colour variation viz., yellowish, white, dull white and purple (Plate 1. A). Out of ten isolates, four isolates FOL-R3, FOLV8, FOL-M6 and FOL-R9 were showed purple colony, isolates FOL- B7, and FOLS10 showed dull yellowish, three isolates
FOL-A2, FOL-F1, and FOL-L4 were white colony and isolate FOL-S5 was Dull white in colour.

\section{Substrate colour}

Colonies of ten isolates differed considerably with regard to their colour/pigmentation on upper as well as lower side of Petri dish. The four types of substrate coloure were found as purple, light puff; white and yellowish (plate 1. B). Out of 10 isolates, 4 isolates FOL-R3, FOL-V8, FOL-M6 and FOL-R9 were Purple, were dull yellowish, isolates FOL- B7, and FOL-S10, four isolates like FOL-A2, FOLL4,FOL-S5and FOL-S10 were white FOLF1was light puff in colour.

\section{Growth pattern}

The $F$. oxysporum f. sp. lentis isolates exhibited mainly three types of growth pattern as appressed, partially appressed and fluffy (Plate 1.B). Out of 10 isolates, four isolates FOL-A2, FOL-L4, FOL-V8 and FOL-M6 were fluffy, four isolates FOL-F1, FOL-S5, FOL- B7 and FOL-S10were appressed and isolates FOL-R9, and FOL-R3were partially appressed type of growth pattern.

\section{Growth}

F. oxysporum f.sp. lentis isolates differed in rate of their mycelial growth as slow, medium and fast. Out of ten isolates, four isolates FOL-F1, FOL-S5, FOL-A2 and FOL-S10 were slow growing, three isolates FOL-L4, FOL-M6 and FOL-R9 were medium growing and three isolates FOL-R3, FOL- B7 and FOL-V8 were fast growing type.

\section{Growth rate}

F. oxysporum f.sp. lentis isolates differed in rate of their mycelial growth rate ( $\mathrm{mm} / 7$ days) as slow, medium and fast. 
Table.1 Cultural characters of different isolates of Fusarium oxysporum f. sp. lentis

\begin{tabular}{|l|l|l|l|l|l|}
\hline Sr.no. & $\begin{array}{l}\text { Name of } \\
\text { isolates }\end{array}$ & Mycelial colour & $\begin{array}{l}\text { Sulostrate } \\
\text { colour }\end{array}$ & Growth pattern & Growth \\
\hline $\mathbf{1}$ & FOL-F1 & White & Dull white & Appressed & Slow \\
\hline $\mathbf{2}$ & FOL-A2 & White & White & Fluffy & Slow \\
\hline $\mathbf{3}$ & FOL-R3 & Purple & Purple & Partially appressed & Fast \\
\hline $\mathbf{4}$ & FOL-L4 & Whitish & White & Fluffy & Medium \\
\hline $\mathbf{5}$ & FOL-S5 & Dull white & White & Appressed & Slow \\
\hline $\mathbf{6}$ & FOL-M6 & purple & Purple & Fluffy & Medium \\
\hline $\mathbf{7}$ & FOL- B7 & Dull yellowish & Light buff & Appressed & Fast \\
\hline $\mathbf{8}$ & FOL-V8 & Purple & Purple & Fluffy & Fast \\
\hline 9 & FOL-R9 & Purple & Purple & Partial appressed & Medium \\
\hline 10 & FOL-S10 & Dull yellowish & White & Appressed & Slow \\
\hline
\end{tabular}

Table.2 Morphological characters of different isolates of Fusarium oxysporum f. sp. lentis

\begin{tabular}{|c|c|c|c|c|c|}
\hline \multirow[t]{2}{*}{ Isolate } & \multicolumn{2}{|c|}{ Microconidia } & \multicolumn{2}{|c|}{ Macroconidia } & \multirow[t]{2}{*}{ Chlamydospore } \\
\hline & Size $(\mu \mathrm{m})$ & Septation & Size $(\mu \mathrm{m})$ & Septation & \\
\hline FOL-F1 & $10.80 \times 3.67$ & $0-1$ & $28.45 \times 4.09$ & $2-4$ & Intercalary and terminal \\
\hline FOL-A2 & $13.21 \times 3.55$ & $0-1$ & $24.11 \times 4.67$ & $2-5$ & Intercalary and terminal \\
\hline FOL-R3 & $12.68 \times 3.79$ & $0-1$ & $25.06 \times 4.21$ & $2-3$ & Intercalary and terminal \\
\hline FOL-L4 & $7.30 \times 3.43$ & 0 & $35.15 \times 4.55$ & $2-5$ & Intercalary and terminal \\
\hline FOL-S5 & $10.35 \times 3.40$ & $0-1$ & $38.72 \times 4.25$ & $3-6$ & Intercalary and terminal \\
\hline FOL-M6 & $9.43 \times 2.67$ & $0-1$ & $30.07 \times 4.03$ & $3-5$ & Intercalary and terminal \\
\hline FOL- B7 & $10.90 \times 2.75$ & $0-1$ & $37.59 \times 4.45$ & $2-4$ & Intercalary and terminal \\
\hline FOL-V8 & $12.28 \times 3.54$ & $0-1$ & $40.05 \times 4.71$ & $2-5$ & Intercalary and terminal \\
\hline FOL-R9 & $12.78 \times 3.57$ & $0-1$ & $31.57 \times 4.00$ & $3-6$ & Intercalary and terminal \\
\hline FOL-S10 & $13.25 \times 2.68$ & $0-1$ & $34.61 \times 4.47$ & $2-5$ & Intercalary and terminal \\
\hline
\end{tabular}

Out of ten isolates, four isolates FOL-F1(5.8), FOL-S5(5.9), FOL-A2 (6.1) and FOL-S10 (6.4) were slow growing, three isolates FOLL4(7.5), FOL-M6(7.3) and FOL-R9 (7.6) were medium growing and three isolates FOL-R3(8.6), FOL- B7 (8.9) and FOL-V8 (8.7) were fast grow rating type.

A study on morphological characters of different isolates of $F$. $o$ f. sp. lentis was carried out under laboratory conditions by using seven, 15 days old culture for observing microconidia, macroconidia and chlamydospores respectively and the results were presented in table 2 reveals that morphological characters were taken into consideration to assess the existence of variation in spore size and septation. Microconidia were observed in all isolates with 0 to 1 septa.

Among the isolates size of microconidia varied between $7.30 \times 3.43$ (FOL-L4) to 13.25 x $2.68 \mu \mathrm{m}$ (FOL-S10). Septa were absent in isolate FOL-L 4. Across the isolates the size of macroconidia varied from $24.11 \times 4.67$ (FOL-A2) to $40.05 \times 4.71 \mu \mathrm{m}$ (FOL-V8). The isolates did not show much variation among 
themselves with regard to septation. However, the number of septa in macroconidia of all the isolates ranged between 2 to 6 . Formation of chlamydospores was observed in all the isolates. They were found single, paired and sometimes in chain, both in intercalary as well as terminal and hyline in colour.

Ten isolates of $F$. oxysporum $\mathrm{f}$. sp. lentis were isolated from infected plant roots and stem from ten districts on Uttar Pradesh. The morphological characters of the fungus were studied after isolating the fungus on Potato Dextrose Agar medium. The fungus produced microconidia, macroconidia and chlamydospores. The size of microconidia varied between $7.30 \times 3.43$ (FOL-L4) to 13.25 $\mathrm{x} 2.68 \mu \mathrm{m}$ (FOL-S10) with 0 to 1 septa. Macroconidia size varied from $24.11 \times 4.67$ (FOL-A2) to $40.05 \times 4.71 \mu \mathrm{m}$ (FOL-V8) with 2 to 6 septa. The isolates did not show much variation in septation. Formation of chlamydospores was observed in all the isolates. They were found single, paired and sometimes in chain, both in intercalary as well as terminal and hyline in colour. Colonies of ten isolates were produces yellowish, white, dull white and purple colour. Out of ten isolates, four isolates FOLR3, FOL-V8, FOL-M6 and FOL-R9 were showed yellowish colony, two isolates FOLB7, and FOL-S10 showed white colour, three isolates FOL-A2, FOL-F1, and FOL-L4 were white colony and isolate FOL-S5 was Dull white in colour. The four types of substrate colour were found as purple, light buff, white and yellowish. Out of 10 isolates, 4 isolates FOL-R3, FOL-V8, FOL-M6 and FOL-R9 were Purple, two isolates yellowish, isolates FOL- B7, and FOL-S10, three isolates FOLA2, FOL-F1, and FOL-L4 were dull white and isolate FOL-S5 was white in pigmentation. Three types of growth pattern as appressed, partially appressed and fluffy is found in all isolates. Out of 10 isolates, four isolates FOL-A2, FOL-L4, FOL-V8 and
FOL-M6 were fluffy, four isolates FOL-F1, FOL-S5, FOL- B7 and FOL-S10 were appressed and six isolates FOL-R9 and FOLR3were partially appressed. F. oxysporum f. sp. lentis isolates differed in rate of their mycelial growth as slow, medium and fast. Out of ten isolates, four isolates FOL-F1, FOL-S5, FOL-A2 and FOL-S10 were slow growing, three isolates FOL-L4, FOL-M6 and FOL-R9 were medium growing and three isolates FOL-R3, FOL- B7 and FOL-V8 were fast growing

\section{References}

Abraham, R. 2015. Lentil (Lens Culinaris Medikus) Current Status and Future Prospect of Production in Ethiopia. Adv. Plants Agric Res 2 (2): 00040.

Ahmad, D. K. Sinha and K. M. Singh, 2017. Economic Analysis of Production and Instability of Lentil in Major Lentil Growing States of India. Int. J. Pure App. Bio. Sci. 6 (1): 593-598.

Anonymous, 1999. Technology for increasing pulses production In India. Indian Institute of Pulses Research, Kanpur. pp. 1-108.

Chaudhary, R. G., Singh, R.K., 2008. Effect of culture media on growth and pigmentation of Fusarium oxysporum $\mathrm{f}$. sp. lentis isolates. J. Food Legumes 2(4), 259-261.

Haware, M. P. and Nene, Y. L. 1980. Influence of wilt at different stages on the yield loss in chickpea. Trop. Grain Legume Bullet. 19: 38-40.

Haware, M. P., Nene, Y. L. and Mathur, S. B. 1986. Seed borne disease of chickpea. Technical Bulletin 1.Danish Government Institute of seed Technology for developing countries. Copenh., 1:1-32.

Haware, M. P., Nene, Y. L. and Rajeswari, R. 1978. Eradication of Fusarium oxysporum f. sp. ciceris transmitted in 
chickpea seed. Phytopathology 68: 1364-1368.

Nath1, N., A. U. Ahmed, F. M. Aminuzzaman., 2017. Morphological and physiological variation of Fusarium oxysporum f. sp. ciceri isolates causing wilt disease in chickpea International Journal of Environment, Agriculture and Biotechnology (IJEAB). Vol-2, Issue-1, pp. 222

Nene, Y. L., Reddy, M. V., Haware, M. P., Ghanekar, A. M. and Amin, K. S. 1991.
Field diagnosis of chickpea disease and their control. In: Information Bulletin no. 28. ed. by International Crops Research Institute for the Semi-Arid Tropics, Patancheru, India.

Rahman, T., Ahmed, A.U., Islam, M.R., and Hosen, M.I. 2010. Physiological study and both in vitro and in vivo antifungal activities against Stemphylium botryosum causing Stemphylium blight disease in lentil (Lens culinaris). Plant Pathology Journal9 (4): 179-187.

\section{How to cite this article:}

Khushboo Dubey and Sushil Kumar Singh. 2018. Study Cultural, Morphological and Pathogenic Variation among Different Isolates of Fusarium oxysporum f. sp. lentis. Int.J.Curr.Microbiol.App.Sci. 7(09): 170-175. doi: https://doi.org/10.20546/ijcmas.2018.709.021 